\title{
Study of Psychological Satisfaction of Population with Services of the Primary Health Care Integrated into Public Health
}

\author{
Nabi Yessimov ${ }^{1, \#,{ }^{*}, \text { Nailya Izmailova }}{ }^{2, \#}$ and Dauletkhan Yessimov ${ }^{3, \#}$ \\ ${ }^{1}$ Kazakhstan School of Public Health, Almaty, Republic of Kazakhstan \\ ${ }^{2}$ Kazakh Medical University of Continuing Education, Almaty, Republic of Kazakhstan \\ ${ }^{3}$ National Chamber of Health, Nur-Sultan, Republic of Kazakhstan
}

\begin{abstract}
The article aims to examine public opinion to achieve a synergistic effect and thereby integrate primary patient feedback in the organization of the promotion of primary care and public health. The leading method to the study of this problem is the questionnaire survey that has afforded revealing issues of regulation of primary and public health care, and in particular, the state of the psychological attitude of patients to primary health care integrated into the public health system of the Republic of Kazakhstan. In order to study the organization of the Primary Health Care System integrated into Public Health Service, 400 healthcare workers were questioned. The authors also analyzed socio-psychological factors that affect the quality of the provision of qualified primary health care. The practical novelty of the study is that the organization of the synergic system of primary health care and public health is implemented based on the public administration system and local systems of public health evaluation. It was concluded that it is more expedient to build a system of integration of primary health care and public health based on feedback from the people and a formation of a spatially distributed network of public medical organizations, which will reduce the burden on, particularly busy areas.
\end{abstract}

Keywords: Patient, medical service, public health care, integration, modernisation.

\section{INTRODUCTION}

There are several options for the development of local public medical services: individual practice, group (brigade) practice, and centres of general practice. The experience of many countries has shown that the lower the level of Private Health Care Systems (PHCS), the more costly and less effective the entire healthcare system is. Different countries have different models of the organization of primary health care. The model primarily includes a family doctor and small outpatient centres, which is also implemented in the PHCS of the Republic of Kazakhstan (RK). In order to achieve the goals of PHCS, the interests of people must be the focus of the network. Implementation of this postulate is possible when the system of medical education is efficient, and public authorities coordinate their efforts [1].

In the RK, most doctors are accustomed to ready data, and the feedback from the patients does not always coincide with the declared goals. In other words, medical standards that determine the Public Health Service (PHS) content are established based on model groups and are sometimes determined empirically. In order to implement a more advanced model, PHCS should be integrated in PHS in the form of a subsystem. During the work of medical staff,

${ }^{*}$ Address correspondence to this author at the Republican Scientific and Practical Center of Mental Health, Almaty, Republic of Kazakhstan; Tel: +7(727) 33780 28; E-mail: nabi-4256yessim@murdoch.in

\#These Authors are equally contributed. doctors' awareness about the patient conditions will increase, which will require retraining of a significant number of doctors for closer contact with the patients and greater implementation of family and general practice systems. In this regard, there is a need to model PHS integration's effectiveness as part of the localization of the PHCS.

Medical education in the European Union (EU) is regulated by EU Directive 93/16, which is intended mainly to ensure the free movement of doctors within the EU [2]. Health care systems in Europe, similar to the rest of the world, are being reformed to reflect changes in the demographic situation, development of medicine, and economic aspects of health care. Depending on the needs and expectations of patients, new methods of health care provision are being developed [3]. For the effective operation of the local PHCS integrated into PHS, all participants of the process realize the key role of the local PHCS integrated into PHS in the health system and the complexity of its tasks [4]. Funding increase for the development of the local PHCS integrated into PHS is used both for salaries of the participants and health care infrastructure to meet the needs of the patients and for education, research, and improvement of the quality of health care [5]. Social workers monitor the health of people with disabilities at home due to illnesses, participants in hostilities, long-livers, deliver free medicines and provide medical care to needy patients [6]. As necessary, organize hospitalization in a hospital, invite specialized specialists and 
psychologists to a house for consultation, teach relatives the rules of patient care, help in solving social issues, and much more.

Innovative technologies are widely used in developed countries to increase the efficiency of the local PHCS integrated into Health Care Services (HCS) [7]. Synchronization and backup of this information are usually carried out using the Internet services Carbonite and Dropbox [8]. A special program facilitates the receipt of payments from insurance companies. Web sites enable patients to make an appointment via the Internet (number of such patients already reaches $70 \%$ ), obtain test results, and order medications, which reduces the number of phone calls per day by $30-50 \%$ [9]. An essential point in managing a local PHCS integrated into HCS is that telemedicine and other remote healthcare technologies play a key role in the work of a doctor [10].

Tele-consultation, telemonitoring, and distance education have become an integral part of the local PHCS integrated into HCS, which is considered a priority at the stage of the health care system reforms. The system of remote records and translation of physiological parameters raised the parameters of the local PHCS integrated into HCS to a qualitatively new level [11]. Telemedicine is a modern medical trend based on the use of telecommunications for a targeted exchange of medical information between specialists to improve the quality and accessibility of diagnostics and treatment [12]. Currently, doctors are increasingly using telephones, faxes, and the Internet to get advice from their colleagues [13].

The European Community funds international projects aimed at developing various aspects of telemedicine for health care workers (for example, the HOMER-D project) [14]. A selective survey among the American health care professionals showed that $89 \%$ of healthcare professionals regularly use the Internet to supplement their knowledge, improve work efficiency, and communicate with patients and specialties [15]. The researchers note that information from the Internet to a certain extent affects the diagnosis and drug choice for the patients [16]. A key component of the foundation of rural medicine in many countries is a general practitioner (GP), but in the United States and many European countries, there is a disparity between the required number of rural doctors and specialists trained annually in medical universities [17]. The number of graduates who want to work specifically in rural areas is significantly higher among the natives, compared to the townspeople, which is mainly related to working conditions [18].

According to the comparative analysis of wages, which harmonizes data based on the theory of absolute purchasing power parity, salaries are high in the USA, lower in the UK, the Netherlands, and Switzerland, even lower in Denmark and Canada, then in Australia and France, and much lower in Belgium, Portugal, Finland and Sweden [19]. According to experts, to provide medical care at the appropriate level, one should constantly increase prestige, ensure good working conditions, and establish salaries according to the results of the work. Doctors should be interested in raising their professional level and quality of work. In some countries, there is a practice of increasing wages in proportion to the number of older people treated [20]. However, issues of salary as the main motivational aspect of effective work organizations are also problematic in developed countries. In Germany, for example, they are solved with public involvement.

The article aims to examine public opinion to achieve a synergistic effect and thereby integrate primary patient feedback in the organization of the promotion of primary care and public health. The objectives of the study are:

- to analyse scientific literature and the World Health Organization (WHO) recommendations;

- to study the socio-psychological factors that affect the quality of the provision of qualified primary health care;

- $\quad$ to justify the functional and organizational model for improving the operation of the PHCS integrated into PHS.

\section{MATERIALS AND METHODS}

We have used the online survey, which consists of a higher level of respondents' readiness to participate in the study and the possibility of choosing a more convenient time to answer the questions. This method increases result credibility, saves resources, ensures a larger sampling size and coverage (access to different social groups and communities), focus (ability to form a specific sampling), relevance (independence) and communication, i.e., the lower influence of the interviewer on the respondent and a high level of anonymity.

The authors determined the population group that formed the general population: 
- a group of the economically active population, a productive part for the country's economy as a representative of a socially-oriented market economy;

- a group of predominantly young people who do not yet have the "burden" of chronic noncommunicable diseases (CNCD);

- $\quad$ groups with an unbiased view on the subject of the local PHCS integrated into PHS;

- a group of people whose representatives were not patients at the time of the survey and therefore were not prejudiced against the local PHCS integrated into PHS;

- urban groups as representatives of the demographic parameter of the population's predominant distribution in the cities (70\%);

- groups with higher access to Internet technologies.

The questionnaire, specially developed using the Google Forms, consisted of 5 sets. The first set of questions concerned the respondents' social status (age, place of residence, employment, and education), which is important for the future public participation in improving the organization of the local PHCS. The second set of questions concerned the determination of the frequency of seeking advice in the local PHCS integrated into PHS, which is important in the development of organizational measures to enhance public contacts with the local PHCS integrated into PHS for the prevention of mental and physical diseases. The third set of questions concerned the efficiency of the services of the local PHCS integrated into PHS. In the fourth set of questions concerning the satisfaction of the population with the services of the local PHCS integrated into PHS, special attention was paid to the attitude of the population, in case of dissatisfaction, to the services in the future to develop organizational measures for the priority development of primary health care. The fifth set of questions was important for the study of public awareness about patient rights and services of the local PHCS integrated into PHS. During the sixth organizational stage, the functional and organizational model for improving the operation of the PHCS integrated into PHS was justified in the new conditions of a socially-oriented market economy.

The questionnaire was sent as a link in the social network to potential respondents, which included a request to join a psycho-sociological survey to study the population's satisfaction with the doctor's services for the prevention of CNCDs. In order to study the organization of the PHCS integrated into PHS, 400 healthcare workers were questioned. The respondents were residents of Almaty. The request specified that the survey was anonymous, and the data obtained would be used for scientific research. Answers of the respondents were automatically entered into the database in the Excel format for further analysis. To determine the minimum sample size, sufficient to meet study objectives, it was necessary to estimate the frequency of choosing answers to the questions. Based on the estimation of the error of representativeness at 95\% confidence level:

$\Delta=1.96 \sqrt{\frac{P(100 \%-P)}{n}}$

where $\mathrm{P}$ - frequency of choice of the answer (\%), $\Delta-$ error of the frequency assessment (\%), n - minimum sample size sufficient to achieve the specified accuracy of the assessment, $n-$ calculated value. The assessment was carried out for $\Delta=5 \%$ (95\% interval $\mathrm{V}$ $=10 \%$ ), for $P=50 \%$ (maximum value of the sample size). The calculation result was $n=385$ respondents.

Further study was carried out regarding the assessment of the local PHCS integrated into PHS and the organization of its work. A questionnaire was specially designed for this study. The sample size was calculated: 12382 - the general population

$n=\frac{N t^{2} \sigma^{2}}{N \Delta_{x}^{2}+t^{2} \sigma^{2}}$

where $\mathrm{N}$ - general population; $\mathrm{n}$ - sample size, required number of observations; $\sigma 2$ - mean square deviation (variance 0.25); $\mathrm{t}$ - confidence coefficient (equal to 2); $\Delta \mathrm{x}$ - maximum sampling error (0.05, which ensures the reliability of results in 95 cases out of 100 with a maximum error $\pm 5 \%$ ).

$n=\frac{12382 * 2^{2} * 0.25}{12382 * 0.05^{2}+2^{2} * 0.25} \approx 400$

In order to determine the acceptability of the proposed functional and organizational model for the improvement of the PHCS integrated into PHS, its expert evaluation was carried out. A special questionnaire was developed for this. The expert group consisted of 25 independent health professionals and social medicine researchers, including 4 MDs and 8 
PhDs. Health care and the PHCS integrated into PHS managers had the highest certification category, which confirmed their competence. The experts evaluated each innovation according to a 10-point scale: from 1 to 10 points. Within 25 minutes, experts assessed the proposed innovations. It was taken into account that expertise is a useful tool for subject analysis and helps to study its qualitative characteristics and practical value.

The mean value $(X)$ and standard deviation $( \pm S D)$ of the parameters were calculated for the study's quantitative results. To evaluate the consistency of the results of expert evaluation, the relative standard deviation was calculated. For qualitative parameters, the parameter rate (\%) and standard error $( \pm \mathrm{m} \%)$, in some cases, also a $95 \%$ confidence interval (95\% V) were calculated. To establish causal relationships for the problem, to identify factor signs and assess the strength of their influence, the method of multifactor logistic regression models was used. Evaluation of model qualities was carried out using the chi-square test and the curves of operating characteristics Receiver Operating Characteristic (ROC-curves). To assess the adequacy of multivariate mathematical models, areas under the ROC curve - Area Under Curve (AUC)- were also used; $95 \% \mathrm{~V}$ was also calculated. To assess the degree of influence of factor signs on the results, the odds ratio (OR) and its $95 \% \mathrm{~V}$ were calculated. For all statistical tests, the critical significance level was 0.05 .

All procedures performed in studies involving human participants were in accordance with the ethical standards of the institutional and national research committee and with the 1964 Helsinki declaration and its later amendments or comparable ethical standards. A study was approved by the Central (National) Ethics Commission of the Ministry of Health of the Republic of Kazakhstan, March 13, 2020, No. 1263-O. Informed consent was obtained from all individual participants included in the study.

\section{RESULTS}

During the questionnaire, 418 answers were received, but in 18 cases, the questionnaires were not completely filled; therefore, they were not taken into account during statistical processing. Thus, 400 respondents were interviewed. A sociological study was conducted during meetings of doctors and experts from the districts of the city of Almaty. The questionnaires were distributed, collected, and statistically processed, thereby preserving the confidentiality of respondent data. The largest group of respondents were young people under the age of 40 $(77.5 \pm 2.2 \%)$, and respondents from 40 to 70 years old $-20.3 \pm 2.0 \%$ (Table 1). In the study, women were more active $(68.2 \pm 2.4 \%)$ compared with men- $31.8 \pm 2.3 \%$.

Table 1: Distribution of Respondents by Age

\begin{tabular}{|c|c|}
\hline Age of doctors $(\% \pm \mathbf{m} \%)$ & Age of doctors $(\% \pm \mathbf{m} \%)$ \\
\hline \hline $18-20$ years & $2.3 \pm 0.9$ \\
\hline $21-30$ years & $53.5 \pm 2.5$ \\
\hline $31-40$ years & $24.0 \pm 2.1$ \\
\hline $41-50$ years & $14.0 \pm 1.8$ \\
\hline $51-60$ years & $5.5 \pm 1.1$ \\
\hline $61-70$ years & $0.8 \pm 0.4$ \\
\hline Total & 100 \\
\hline
\end{tabular}

Respondents who joined the survey primarily had higher education $(87.5 \pm 1.7 \%)$ and undergraduate higher education $(7.8 \pm 1.3 \%)$, which is important to find out how highly educated people are aware of the institute of the PHCS integrated into PHS. 16 $(4.3 \pm 1.0 \%)$ respondents with secondary special education, $3(0.8 \pm 0.4 \%)$ respondents with secondary education participated in the survey. Among respondent, $73.5 \pm 2.2 \%$ informed that they work, $9.3 \pm 1.4 \%$ keep house, $8.5 \pm 1.4 \%$ study, $7.8 \pm 1.3 \%$ are unemployed, and $1.0 \pm 0.5 \%$ are pensioners.

The second part of the questions was related to the frequency of visits to PHCS integrated into PHS, for the selected category of the population, which is important for the development of organizational measures to enhance public contacts with PHCS integrated into PHS in order to prevent noncommunicable diseases. It was found that only $7.0 \pm 1.3 \%$ of the respondents had a so-called "own" health care provider. Among the other respondents, $19.3 \pm 2.0 \%$ do not have a permanent health care provider. The majority $(86.0 \pm 1.7 \%)$ of the respondents said that they are aware of the right to choose and change the attending physician freely, $6.3 \pm 1.2 \%$ were not aware, and $7.8 \pm 1.3 \%$ stated they don't have that right. The majority $(55.0 \pm 2.5 \%)$ of the respondents told that they are not aware of the territorial proximity to the place of residence or the location of the medical organization where they can receive primary health care, including $36.5 \pm 2.4 \%$ who do not know where to receive such information, and $22.5 \pm 2.1 \%$ want to have, but do not know where and 
how to apply. These results indicate that the WHO principle on the continuity of primary health care, constant medical supervision not only for disease but also for advisory counseling, contributes to the prevention of CNCD. This also shows the lack of awareness about PHCS integrated into PHS.

$59.0 \pm 2.5 \%$ respondents answered that in case of emergency they would seek medical help from a doctor and choose a specialized doctor; $23.3 \pm 2.1 \%$ will do tests first or another investigation, and then visit a doctor, which is unreasonable from the point of view of a modern healthcare organization, since inefficient loading of specialized doctors is a high-risk technology. In addition, a number of social factors of a patient's life affect the state of a patient's health, It remains out of sight of a specialized doctor; $14.7 \pm 1.8 \%$ indicated that they would contact their "own" and $3.0 \pm 0.9 \%$ will visit any doctor. The results confirm the population's lack of awareness about the procedure and the possibility of obtaining primary health care. During the last year, $15.5 \pm 1.8 \%$ of the respondents sought medical help. According to the results, the majority $(60.5 \pm 2.4 \%)$ of the respondents chose a doctor in the state medical organization. Of those that visited a specialized doctor, $36.2 \pm 2.4 \%$ chose this specialist in a private medical organization.

The third part of the questions was about the effectiveness of the services of PHCS integrated into PHS. The responses for the following questions were analysed: "If you sought medical care, were you treated or referred to another specialist doctor?" and "If the doctor treated you, did you recover or have complications?" The answers obtained indirectly indicate the possibilities of PHCS integrated into PHS independently provide care and allow evaluating the effectiveness of services on the prevention of CNCD. Among respondents, $67.5 \pm 2.4 \%$ did not seek medical help. Among $32.5 \pm 2.3 \%$ of respondents (130 people) who sought medical help, $57.0 \pm 2.5 \%$ (74 people) received medical care directly from the doctor, of which $81.0 \pm 2.0 \%$ recovered (60 people), which indicates the prospects of primary health care and the doctor-patient relationship. However, one of five had complications $(19.0 \pm 2.0 \%)$. In a significant amount $(42.5 \pm 2.5 \%)$ of visits, the doctor referred patients to another doctor. This probably indicates a lack of ability of doctors to provide patients with effective primary health care.

The fourth part of the questions concerned public satisfaction with the services of PHCS integrated into PHS. Special attention was paid to clarifying the population's attitude, in case of dissatisfaction, to services in the future to develop organizational measures for the priority development of primary health care. Almost half $(45.2 \pm 2.5 \%)$ of patients who were medically treated were dissatisfied with the quality of medical care provided, of which $33.7 \pm 2.4 \%$ refused any further services. $45.2 \pm 2.5 \%$ of patients dissatisfied with the quality of medical care did not refuse further services, the majority of patients $(52.6 \pm 2.6 \%)$ did not replace the doctor, $2.3 \pm 0.9 \%$ replaced the doctor, and $31.6 \pm 2.3 \%$ visited another specialist. The results indicate a significant reserve of public confidence in doctors' practice, which must be used in the development of measures to improve their work.

The fifth part of the questions was important for studying the level of public awareness about patient's rights and services of PHCS integrated into PHS, since the lack of public awareness may be an independent cause of the ineffectiveness of primary health care. Since the prevention of CNCD includes counseling, the questionnaire includes questions about obtaining information from the doctor about the prevention of major diseases and lifestyles.

One of the main functions of the work and effective methods of preventing diseases is providing patients with educational information. Only $54.25 \pm 2.5 \%$ of the respondents interviewed by the doctor answered the question "Did the doctor talk with you about disease prevention?", $25.5 \pm 2.2 \%$ of patients did not receive information, and $19.5 \pm 2.0 \%$ considered the doctor incompetent. The data obtained indicate that the doctor had either an insufficient level of qualification or insufficient training in communication. Educational topics suggested by the doctor: the prevention of hypertensive disease $(5.5 \pm 1.1 \%)$, the prevention of sexually transmitted infections $(1.5 \pm 0.6 \%)$, proper nutrition, family planning, use of contraceptive methods for a healthy lifestyle, incl. physical exercises, physical movement, use of fresh air $(0.8 \pm 0.4 \%)$. The majority $(91.5 \pm 2.4 \%)$ of the respondents mentioned that the doctor does not have a decent wage, work organization, and social protection to provide quality medical care.

The method to construct logistic regression models was used to identify the factors associated with the patient's attitude to the doctor. The response to the question: "Do you have your "own" doctor?" was used as a resultant parameter $Y$. In the answer: "Yes, I have" or "No, I do not have, but I want to have", the variable $\mathrm{Y}$ took the value 0 (not the case), otherwise $-\mathrm{Y}=1$. 
According to the factor signs, 7 variables were the responses for the questionnaire: "If you have an urgent need to seek help from a doctor, who will you choose?" (X1), "How do you think can you consult a doctor for advice if you fear that you have HIV?" (X2), "Your age (complete years)?" (X3), "Gender" (X4), "Your place of residence" (X5), "What is your education?" (X6), "What do you do now?" (X7) were analysed.

At the first stage of the analysis, stepwise exclusion/addition signs (Stepwise with a critical inclusion level of $p<0.1$ and exclusion level of $p>0.3$ ) were used to select significant risk factors for negative patient-to-doctor attitudes. 6 factor signs $X 1, X 2, X 4$, $X 5, X 6, X 7$ were identified. The model constructed on these signs is adequate $(X 2=130$ at 13 degrees of freedom, $p<0.001)$. Figure 1 shows the characteristic operating curve of the model.

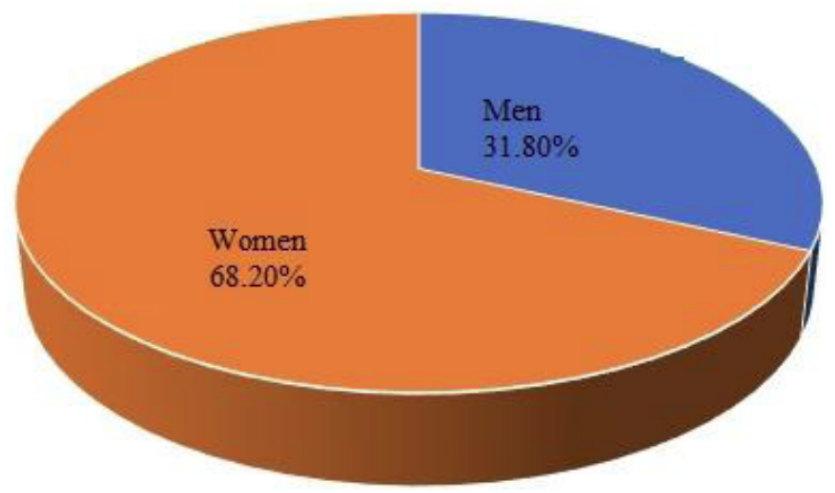

Figure 1: Curve of the operating characteristics of the model predicting the risk of negative of patient-to-doctor attitudes.
The area under the ROC-curve of the model, $\mathrm{AUC}=0.83(95 \% \vee 0.79-0.86)$, which indicates the average severity of the relationship between the risk of the negative attitude of patients to the doctor and the responses for the question: "If you have an urgent need seek medical help from a doctor, you will you choose?", "How do you think can you consult a doctor if you fear that you have become infected with HIV?", "Gender", "Your place of residence", "What is your education?", "What are you doing now?". Table 2 shows the model coefficients.

The analysis revealed the reduced $(p=0.002)$ risk of the patient's negative attitude towards the doctor if the patient first performs tests or other investigations, and then decides which doctor to consult, Vsh $=0.37$ (95\% V $0.20-0.69)$ compared with the values of the "Highly specialized doctor". The reduced $(p<0.001)$ risk of the patient's negative attitude towards the doctor was also revealed if the patient is sure that he has the right to choose or change the doctor freely, Vsh $=0.1(95 \% \mathrm{~V}$ 0.04-0.28) compared to the answer "Not". The increased $(p=0.028)$ risk of the doctor's negative attitude for rural patients was also identified, Vsh $=7.8$ $(95 \% \vee 1.2-49)$ compared with urban residents. The increased $(p=0.009)$ risk of the patient's negative attitude towards the doctor for patients with undergraduate higher education, Vsh $=7.4$ (95\% V 1.733) compared with those with higher education, was established.

Table 2: Coefficients of the Risk Projection Model for Negative Attitudes of Patients Towards the Doctor

\begin{tabular}{|c|c|c|c|}
\hline Factor sign & $\begin{array}{l}\text { Model coefficient } \\
\text { value } b \pm m\end{array}$ & $\begin{array}{l}\text { Significance level difference of } \\
\text { the coefficient from } 0, p\end{array}$ & $\begin{array}{l}\text { Parameter Vsh } \\
\quad(95 \% \mathrm{~V})\end{array}$ \\
\hline X1 = "Any doctor" vs. "Highly specialized doctor" & $-1.12 \pm 0.65$ & 0.082 & - \\
\hline $\begin{array}{c}\mathrm{X} 1 \text { = "I will go first to do tests or other } \\
\text { investigations, and then decide" vs. "Highly } \\
\text { specialized doctor" }\end{array}$ & $-0.98 \pm 0.31$ & 0.002 & $0.37(0.20-0.69)$ \\
\hline X1 = "Family doctor" vs. "Highly specialized doctor" & $-2.37 \pm 0.38$ & $<0.001$ & $0.09(0.04-0.20)$ \\
\hline X2 = "Yes, I can" vs. "No" & $-2.26 \pm 0.5$ & $<0.001$ & $0.1(0.04-0.28)$ \\
\hline X2 = "I don’t know" vs. "No" & $-2.68 \pm 0.52$ & $<0.001$ & $0.07(0.02-0.19)$ \\
\hline X4 = "Male" vs. "Female" & $0.56 \pm 0.3$ & 0.067 & - \\
\hline X5 = "Village" vs. "City" & $2.05 \pm 0.93$ & 0.028 & $7.8(1.2-49)$ \\
\hline X6 = "Undergraduate higher" vs. "Higher" & $2 \pm 0.76$ & 0.009 & $7.4(1.7-33)$ \\
\hline X7 = "Housekeeper" vs. "Unemployed" & $0.85 \pm 0.63$ & 0.179 & - \\
\hline X7 = "Retirement pensioner" vs. "Unemployed" & $0.68 \pm 1.03$ & 0.509 & - \\
\hline X7 = "Student" vs. "Unemployed" & $-0.95 \pm 0.67$ & 0.156 & - \\
\hline X7 = "Employed" vs. "Unemployed" & $0.81 \pm 0.48$ & 0.087 & - \\
\hline
\end{tabular}


According to age, respondents were distributed as follows (Table 3 ). The largest group of respondents includes doctors aged $23-30$ years $(24.4 \pm 2.2 \%)$, and the smallest group included respondents over 60 years old $(1.3 \pm 0.6 \%)$.

Table 3: Distribution of Respondents by the Age of Doctors

\begin{tabular}{|c|c|}
\hline Age of doctors $(\% \pm \mathbf{m} \%)$ & Age of doctors $(\% \pm \mathbf{m} \%)$ \\
\hline \hline 23-30 years & $24.4 \pm 2.2$ \\
\hline $31-35$ years & $12.2 \pm 1.6$ \\
\hline $36-40$ years & $9.4 \pm 1.5$ \\
\hline $41-45$ years & $19.0 \pm 2.0$ \\
\hline $46-50$ years & $12.2 \pm 1.6$ \\
\hline $51-55$ years & $16.2 \pm 1.9$ \\
\hline $56-60$ years & $5.3 \pm 1.1$ \\
\hline Above 61 years & $1.3 \pm 0.6$ \\
\hline Total & 100 \\
\hline
\end{tabular}

Doctors from all three groups participated in the study, which is important to obtain objective information. All the interviewed doctors worked at state medical institutions. The majority $(96.0 \pm 1.0 \%)$ of respondents received training in medicine by retraining at the postgraduate level, including $76.4 \pm 2.1 \%$ retrained as a general practitioner, $13.8 \pm 1.7 \%$ as paediatrician, $1.4 \pm 0.6 \%$ as a surgeon, $2.8 \pm 0.8 \%$ as obstetrician and gynecologist, $5.6 \pm 1.1 \%$ specialized in another medical direction. $4.0 \pm 1.0 \%$ of respondents were trained in primary health care in an internship as a primary specialization. $15.3 \pm 3.9 \%$ of the respondents received qualification training in primary health care by postgraduate retraining and became doctors according to the administration's recommendation. These doctors were proposed the increased salaries, which is a motivational mechanism. Among retrained specialists, $56.6 \pm 2.8 \%$ indicated that when they became primary care physicians at the postgraduate level of education, their salary did not increase.

In $36.3 \pm 2.5 \%$ of cases, respondents who received qualification training in primary health care at the postgraduate level answered that they had sufficient knowledge to provide effective medical care, but a significant part answered that they did not have enough knowledge, in particular on paediatrics. This information indicates the need to include modern approaches to continuous postgraduate education in a set of measures to improve the organization of work.
With regard to personnel training, $81.7 \pm 1.9 \%$ said that they have a certificate in the specialty "primary health care", $18.3 \pm 1.9 \%$ do not have this certificate. $55.0 \pm 2.8 \%$ of certified respondents were qualified in "primary health care". Among them, $33.7 \pm 3.7 \%$ had the highest category, $34.4 \pm 3.8 \%$ had the first category, and $31.9 \pm 3.7 \%$ had the second category.

An essential factor in the effectiveness of medical care is the provision of standardized organizational technologies for medical professional work. Among those surveyed, $50.0 \%$ (95\% $\vee 45.1 \%-54.9 \%)$ told that they have satisfactory, $41.9 \pm 2.5 \%$ have unsatisfactory conditions of work organization, $8.1 \pm 1.4 \%$ did not know the response for this question. The majority $(74.6 \pm 2.2 \%)$ of respondents said that their work organization does not meet the standards established by orders, $20.4 \pm 2.0 \%$ responded that it meets, $5.1 \pm 1.1 \%$ did not know the response question. 58.8\% $(95 \% \vee 53.9 \%$ and $63.7 \%)$ of the respondents were well-informed of the list of available equipment of the outpatient department, $41.2 \pm 2.5 \%$ were not informed.

To identify the factors associated with the motivation of doctors for qualification training in medicine by retraining at the postgraduate level, the method of construction of logistic regression models was used. As a result, $Y$ was used to answer the question: "How did you receive the postgraduate qualification training in medicine and become a general practitioner?". If the response: "By own volition", the variable $Y$ adopted the value 0 (not a case), otherwise $Y=1$. For factor signs, the analysis was performed for 14 variables:

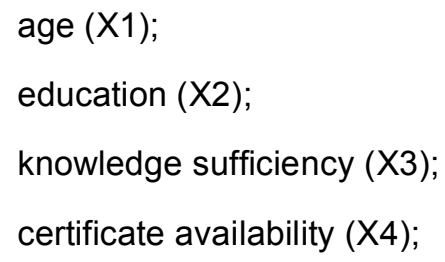
the Republic of Kazakhstan (X8);

- $\quad$ awareness of the list of available equipment (X9);

condition of the health care facility (X10); 
- $\quad$ Internet access (X11);

- $\quad$ car availability (X12);

- $\quad$ availability of housing (X13);

- $\quad$ satisfaction with housing (X14).

At the first stage of the analysis, the method of stepwise exclusion/addition signs (Stepwise at a critical level of inclusion $p<0.1$ and exclusion $p>0.3$ ) was used to select significant risk factors of the reluctance to choose a doctor's work. 4-factor signs were identified: $X 1, X 4, X 6$, and $X 13$. The model built on these features is adequate $(x 2=101$ with 12 degrees of freedom, $p<0.001)$. The characteristic operating curve of the model is shown in Figure 2.

The area under the ROC curve of the model, $A U C=0.84(95 \% \vee 0.80-0.88)$, which indicates the average intensity of the risk connection and the reluctance to choose GPs in the primary health care sector with responses for questions: age (X1), certificate (X4), 5.1 - qualification category (X6), 14 availability of the place of residence (X13).

The coefficients of the model are given in Table 4 . The analysis revealed the reduced risk of reluctance to specialize in primary health care for the age groups of

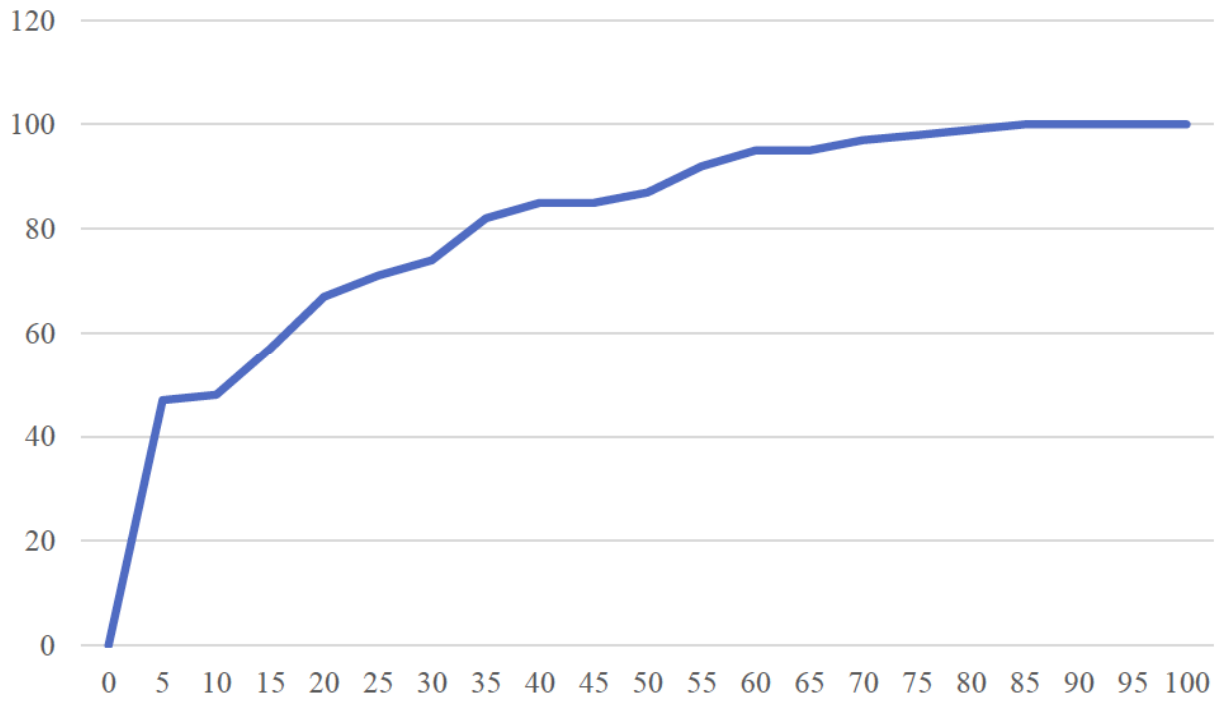

Figure 2: Operating characteristic curve of the prediction model for the wish of the general practitioner to choose primary health care.

Table 4: Coefficients of the Risk Prediction Model of Reluctance to Specialize in Primary Health Care

\begin{tabular}{|c|c|c|c|}
\hline Factor sign & Model coefficient value $b \pm m$ & $\begin{array}{l}\text { Significance level difference of the } \\
\text { coefficient from } 0, p\end{array}$ & $\begin{array}{l}\text { Parameter Vsh } \\
\quad(95 \% \mathrm{~V})\end{array}$ \\
\hline$X 1=31-35$ vs. $23-30$ & $-1.19 \pm 0.63$ & 0.06 & - \\
\hline$X 1=36-40$ vs. $23-30$ & $-1.71 \pm 0.61$ & 0.005 & $0.18(0.05-0.60)$ \\
\hline$X 1=41-45$ vs. $23-30$ & $-0.3 \pm 0.52$ & 0.561 & - \\
\hline$X 1=46-50$ vs. $23-30$ & $0.33 \pm 0.64$ & 0.602 & - \\
\hline$X 1=51-55$ vs $23-30$ & $-2.45 \pm 0.54$ & $<0.001$ & $0.09(0.03-0.25)$ \\
\hline$X 1=56-71$ vs. $23-30$ & $-0.7 \pm 0.64$ & 0.269 & - \\
\hline X4 =No vs Yes & $-1.74 \pm 0.41$ & $<0.001$ & $0.18(0.08-0.39)$ \\
\hline$X 6=$ first vs higher & $2.05 \pm 0.55$ & $<0.001$ & $7.8(2.6-23)$ \\
\hline$X 6=$ second vs higher & $2.21 \pm 0.76$ & $<0.001$ & $9.2(2.1-40)$ \\
\hline X6 = specialist vs & $0.03 \pm 0.4$ & 0.933 & - \\
\hline Higher & $-0.19 \pm 0.51$ & 0.71 & - \\
\hline $\begin{array}{c}\text { X14 = "Employer-rented flat" } \\
\text { vs. "Own flat" }\end{array}$ & $1.3 \pm 0.6$ & 0.031 & $3.7(1.1-12)$ \\
\hline
\end{tabular}


36-40 years old (Vsh=0.18 (95\% M 0.05-0.60)) and 5155 years old (Vsh=0, 09 (95\% M 0.03-0.25)) compared with the age category of 23-30 years; the increased $(p<0.001)$ risk of reluctance to specialize in primary health care for doctors with the first category $=7.8$ (95\% V 2.6-23) compared with those who had the highest qualification category; the increased $(p=0.031)$ risk of reluctance to choose a specialty in primary health care in case of need to rent a flat, Vsh $=3.7(95 \%$ $\checkmark$ 1.1-12) compared to those who had their own flats.

The results suggest that motivational measures should be used for younger physicians to create an incentive to work in the primary health care system.

\section{DISCUSSION}

Respondents expressed their views on the questions identified in the questionnaires. Such questionnaires are essential for the formation of the components for improving the work organization of PHCS integrated into PHS. We have distributed the opinions of patients in the following groups.

Group 1 - the replacement of highly specialized doctors is an absolutely senseless idea that destroys the medical industry, indicating the need to enhance explanatory work for the population about the importance of medicine.

- Group 2 - the service of doctors needs demonopolization to ensure the possibility of choosing public or private doctors for one price, which is also included in the scope of legal regulation.

- Group 3 - advanced training (to improve the trust relationship between the doctor and patient), increasing the doctor's salary and responsibility, and restricting the patient's rights is an urgent need (indicating an understanding of a certain proportion of the population of the problems of medicine).

- $\quad$ Group 4 - medicine is essential. The doctor acts as a health guarantor due to awareness of the health condition from birth, which indicates the importance of motivational measures for the doctor's interest in the effectiveness of their work.

- $\quad$ Group 5 - public awareness regarding medicine needs improvement.

Group 6 - doctors should be trained from the 1st year of study, and the list of diseases treated by the primary health care doctor should be narrowed.

Thus, the results, in particular, the reduced risk of the patient's negative attitude towards the doctor if the patient wishes to make diagnostic studies first instead of visiting "Highly specialized doctor" and when the patient is aware of their rights, and increased risk of the negative attitude of the patient towards the doctor for patients with undergraduate higher education indicates the presence of an unused trust resource of patients towards the doctor, which can be used by raising the level of awareness of the population on the importance of primary health care through the improvement of information technology. The increased risk of a patient's negative attitude towards the doctor for rural vs. urban residents may indicate a lack of access to primary health care for them.

In order to study the opinion of doctors on the provision of organizational technologies for their work, the age of the doctors surveyed is important, since the Republic of Kazakhstan mainly includes three main groups of doctors: district general practitioners of older age who have been retrained in primary health care; older and middle age retrained specialists of different specialties; doctors of young age who have received a specialty at the undergraduate level.

The functional and organizational model for the improvement of the operation of the PHCS integrated into PHS was developed based on the analysis of scientific literature, the WHO recommendations, and study results. All this leads to dissatisfaction with the services of the PHCS integrated into PHS. The following shortcomings were determined:

- uncertainty of the legal responsibility of local governments in cases of failure to ensure the active organization of the operation of the PHCS integrated into PHS;

- the inability of local communities to independently organize and manage health care organizations that provide primary health care:

- $\quad$ lack of special legislation regarding agreements on medical services for the population, which could improve the organizational conditions of the PHCS integrated into PHS;

- $\quad$ the regulatory burden on the PHCS integrated into PHS exceeds the parameters in developed countries; 
- inadequate legislative support for the organization's motivational measures of the operation of the PHCS integrated into PHS and mechanism for their implementation in secondary legislation;

- $\quad$ low provision of doctors per 10 thousand people in urban settlements and vacant staff positions in the PHCS integrated into PHS by individuals, which leads to overload on healthcare workers and deterioration of working conditions;

- insufficient qualification of PHCS managers, which leads to the inefficient organization of the work of the PHCS integrated into PHS;

- unsatisfactory level of material and technical support of the working conditions of doctors;

- lack of public awareness about the institute of primary health care.

The results of the sociological study of work organization technologies confirm the modernization monitoring data, in particular, doctors have inadequate conditions for their work organization (health institution buildings require major repairs, insufficient material, and technical support), require improved qualifications, employer's motivational measures which can promote interest in work and its effectiveness. According to the authors, the activities of doctors must be improved by the autonomization of medical institutions for the prompt regulation of the work organization of doctors and the fund distribution. Summarizing the respondents' recommendations, it can be concluded that the answers show the indifference of the population to the institute of medicine. This requires public educative activities about the positive aspects of the work of PHCS integrated into PHS among the population.

\section{CONCLUSIONS}

Thus, a socio-psychological study of the population's personal attitude to primary health care revealed several factors that may psychologically deter patients from seeking timely medical care. It was examined public opinion to achieve a synergistic effect. Patients are concerned about the lack of qualification of GPs in the sphere of primary health care, the problem of confidentiality between the doctor and the patient, insufficient legal responsibility of the doctor in case of a negative result of treatment, insufficient material, and technical supply.
In general, the Primary Health Care System is integrated into the Public Health Service. At the same time, its management is based on directives and studies of individual sociological institutions. In this regard, the planned efficacy parameters and the formation of a sustainable public health model in the Republic of Kazakhstan are far from reality and, in some cases, are destructive. It is believed that it is more expedient to build a system of integration of primary health care and public health on the basis of feedback from the people and a formation of a spatially distributed network of public medical organizations, which will reduce the burden on, particularly busy areas. This study will be interesting for everyone interested in and works in medicine or health care.

\section{ACKNOWLEDGEMENT}

None.

\section{REFERENCES}

[1] Public health interventions yield big cost savings. Pharmaco Economics \& Outcomes News 2017; 776(1): 29. https://doi.org/10.1007/s40274-017-3931-x

[2] Hancock T. Population health promotion 2.0: An eco-social approach to public health in the Anthropocene. Canadian Journal of Public Health 2015; 106(4): 252-255. https://doi.org/10.17269/cjph.106.5161

[3] Zarowsky Ch. Strengthening systems and scholarship for global health - and public health. Canadian Journal of Public Health 2016; 107(4): 339-341. https://doi.org/10.17269/CJPH.107.5986

[4] Littlejohns LB, Smith N, Townend L. Why public health matters today more than ever: The convergence of health and social policy. Canadian Journal of Public Health 2019; 1 : 4-11. https://doi.org/10.17269/s41997-018-0171-1

[5] Allen P. Lessons learned in promoting evidence-based public health: Perspectives from managers in state public health departments. Journal of Community Health 2018; 43(5): 856863.

https://doi.org/10.1007/s10900-018-0494-0

[6] Ndumbe-Eyoh S, Mazzucco A. Social media, knowledge translation, and action on the social determinants of health and health equity: A survey of public health practices. Journal of Public Health Policy 2016; 37(2): 249-259. https://doi.org/10.1057/s41271-016-0042-z

[7] Gray SF, Evans D. Developing the public health workforce: Training and recognizing specialists in public health from backgrounds other than medicine: Experience in the UK. Public Health Reviews 2018; 39(1): 14. https://doi.org/10.1186/s40985-018-0091-x

[8] Brand A, Evangelatos N, Satyamoorthy K. Public health genomics: The essential part for good governance in public health. International Journal of Public Health 2016; 61(4): 401-403.

https://doi.org/10.1007/s00038-016-0828-6

[9] McLaren L, Figueiredo R. Special section on dental public health: A collaboration between the Canadian Journal of Public Health and the Canadian Association of Public Health Dentistry. Canadian Journal of Public Health 2017; 108(3): 219-220.

https://doi.org/10.17269/CJPH.108.6347 
[10] Frew E. Aligning health economics methods to fit with the changing world of public health. Applied Health Economics and Health Policy 2017; 15(3): 287-289. https://doi.org/10.1007/s40258-017-0319-9

[11] Inekweazu Ch. A north/south collaboration between Two National Public Health Institutes - A model for global health protection. Journal of Public Health Policy 2015; 36(2): 181193.

https://doi.org/10.1057/jphp.2014.52

[12] Garden R. Critical healing: Queering diagnosis and public health through the health humanities. Journal of Medical Humanities 2018; 1: 2-5. https://doi.org/10.1007/s10912-018-9533-1

[13] Wilk P, Cooke M, Stranges S, Maltby A. Reducing health disparities among indigenous populations: The role of collaborative approaches to improve public health systems. International Journal of Public Health 2018; 63(1): 1-2. https://doi.org/10.1007/s00038-017-1028-8

[14] Do public health reforms to reduce antibiotic overuse work? Pharmaco Economics \& Outcomes News 2018; 802(1): 11 https://doi.org/10.1007/s40274-018-4902-6

[15] Mulinari Sh, Davis C. Regulatory scientists' work has important ramifications for public health and should be open to public scrutiny. Health Research Policy and Systems 2018; 16(1): 98

https://doi.org/10.1186/s12961-018-0371-4
[16] Evangelatos N, Satyamoorthy K, Brand A. Personalized health in a public health perspective. International Journal of Public Health 2018; 63(4): 433-434. https://doi.org/10.1007/s00038-017-1055-5

[17] Verani AR. Legal and regulatory framework for health worker retention in Mozambique: Public health law research to strengthen health systems and services. Journal of Public Health Policy 2016; 37(3): 369-384. https://doi.org/10.1057/jphp.2016.22

[18] Makenzius M, Wamala S. Swedish public health policy: Impact on regional and local public health practice and priorities. Journal of Public Health Policy 2015; 36(3): 335349. https://doi.org/10.1057/jphp.2015.3

[19] Lee LM, Royo-Bordonada MA. Continuing the conversation about public health ethics: Education for public health professionals in Europe. Public Health Reviews 2015; 36(1): 5. https://doi.org/10.1186/s40985-015-0001-4

[20] Otok R, Foldspang A. Main competences and skills to perform essential public health operations, offered by schools of public health in four European countries: A short pilot report. International Journal of Public Health 2016 61(6): 633-639. https://doi.org/10.1007/s00038-016-0870-4

DOI: https://doi.org/10.6000/2292-2598.2020.08.04.9

(c) 2020 Yessimov et al.; Licensee Lifescience Global.

This is an open access article licensed under the terms of the Creative Commons Attribution Non-Commercial License (http://creativecommons.org/licenses/by-nc/3.0/) which permits unrestricted, non-commercial use, distribution and reproduction in any medium, provided the work is properly cited. 